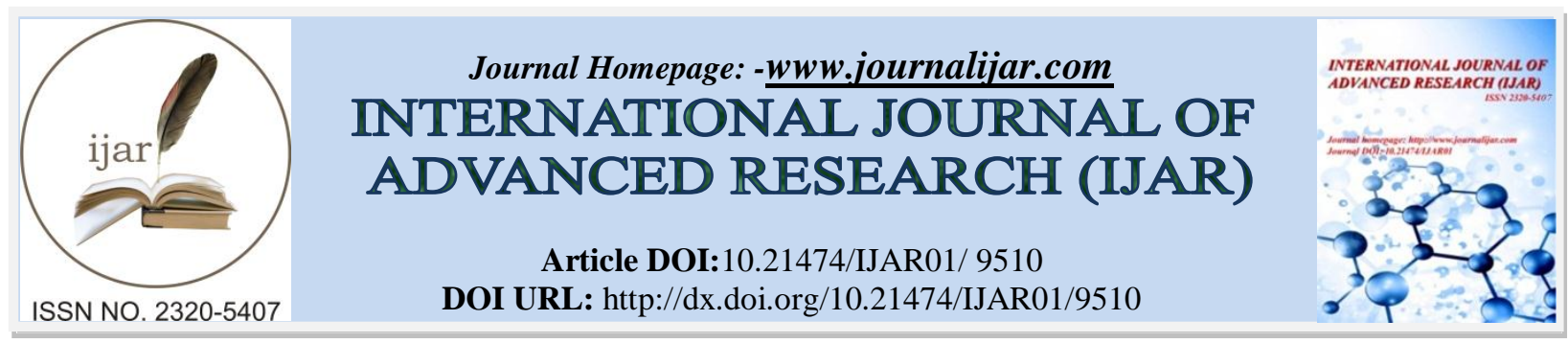

RESEARCH ARTICLE

\title{
EXPLORING BIOMARKERS OF ANEMIA IN NEONATES WITH GLUCOSE-6-PHOSPHATE DEHYDROGENASE DEFICIENCY.
}

Salomon E. M. Fiogbe ${ }^{1}$, Casimir D. Akpovi ${ }^{1}$, Julien G.A. Segbo ${ }^{1}$, Fifamè E.E. Kougnimon ${ }^{1}$, EdgardRoméo S. Tcheoubi $^{1}$, Gratien G. Sagbo ${ }^{2}$ and Clément Agbangla ${ }^{3}$.

1. Non-Communicable Diseases and Cancer Research Unit, Laboratory of Applied Biology Research, EcolePolytechniqued'Abomey-Calavi, University of Abomey-Calavi, Benin, 01BP 2009 Cotonou, Bénin.

2. Medical Genetics and Neonatology, "Centre National Hospitalier et Universitaire H.K. Maga", 01BP 386, Cotonou, Benin.

3. Laboratory of Molecular Genetics and Genome Analyzes, Faculty of Sciences and Technics, University of Abomey-Calavi, 01BP 526, Cotonou, Benin.

\section{Manuscript Info}

\section{Manuscript History}

Received: 06 June 2019

Final Accepted: 08 July 2019

Published: August 2019

Key words:-

G6PD deficiency, newborn, biomarker, anemia, Benin.

\section{Abstract}

Background: Glucose-6-Phosphate Dehydrogenase (G6PD) deficiency is the most common enzymopathy. It induces haemolytic crises with hyperbilirubinemia in newborns and a consequent anemia.

Objective: In this study, we aimed to assess if anemia markers are affected in G6PD deficient newborn in the absence of oxidative attack. Methods: This is a cross-sectional descriptive study carried on in 185 infants aged 7 days and younger in southern Benin. The enzymatic activity of G6PD was assayed with Lactate Dehydrogenase (LDH) and Alkaline Phosphatase ALP) activities, Iron, Total Proteins (TP), reticulocytes levels and hemoglobin $(\mathrm{Hb})$ levels. Data were analyzed with SigmaPlot Statistical Analysis Software 2014. Mean and Standard Errors on the Mean (SEM) of blood parameters were calculated. Student's t-test and Mann-Whitney Rank Sum test were used to ascertain difference between group characteristics. The study was approved by the national ethics committee.

Results: A total of 44 newborns (23.78\%) were G6PD deficient. The Minan and Adja ethnic groups were the most affected with a prevalence of $45.45 \%$ and $40.00 \%$ respectively. The mean level of TP $(57.92 \pm 2.04$ vs. $61.31 \pm 5.01)$, Iron $(1.78 \pm 0.15$ vs. $1.76 \pm 0.44)$ and the enzymatic activity level of PAL $(136.76 \pm 6.69$ vs. $117.33 \pm 5.04)$ and LDH $(291.15 \pm 19.50$ vs. $279.57 \pm 69.32)$ did not vary significantly in severe G6PD deficientneonates compared to normal.

Conclusion: Hemolytic anemia biomarker are not affected in G6PD deficiency neonates.

Copy Right, IJAR, 2019, All rights reserved.

\section{Introduction:-}

Glucose-6-phosphate dehydrogenase (G6PD) is an enzyme that catalyses the first reaction in the pentose phosphate pathway, providing reducing power to all cells through NADPH. NADPH enables cells to counterbalance oxidative

Corresponding Author:-Casimir D. Akpovi. 
stress that can be triggered by several oxidant agents, and to preserve the reduced form of glutathione (Cappellini and Fiorelli, 2008). Since red blood cells do not contain mitochondria, the pentose phosphate pathway is their only source of NADPH. Therefore, defence against oxidative damage is dependent on G6PD in these cells (Mehta et al., 2000).

G6PD deficiency is an X-linked, hereditary genetic defect caused by mutations in the G6PD gene, resulting in protein variants with different levels of enzyme activity (Cappellini and Fiorelli, 2008). G6PD deficiency affects more than 400 millions of people worldwide (Mehta et al., 2000; van den Broek et al., 2016). A striking similarity exists between the areas where G6PD deficiency is common and Plasmodium falciparum malaria is endemic (Ruwende and Hill, 1998). About 7.5\% of the population worldwide are carriers of G6PD deficiency, ranging from $0.1 \%$ in Japan and some European areas to $35 \%$ in Africa, Southern Europe, Middle East, and Southeast Asia (Drousiotou et al., 2004; Noori-Daloii et al., 2007).

G6PD deficiency is associated with a wide range of biochemical and clinical phenotypes (Cappellini and Fiorelli, 2008). Majority of G6PD deficient individuals are asymptomatic most of the time (Howes et al., 2013). Symptoms appeared when cells are exposed to exogenous oxidative stresses against which they cannot defend themselves. The severity of the clinical symptoms and the subsequent treatment required depend on the enzyme deficiency variant, the nature and dose of the oxidative agent, the time course of exposure, the presence of additional oxidative stresses and pre-existing factors such as age, haemoglobin concentration and concurrent infection (Cappellini and Fiorelli, 2008). Neonatal jaundice (NNJ) remains the most clinically serious symptom of G6PD deficiency. NNJ peaks 2 to 3 days after birth (Howes et al., 2013). This is highly variable in severity but can lead to kernicterus and permanent neurological damage or death if left untreated (Doxiadis and Valaes, 1964). Not all neonates with NNJ are G6PD deficient, but this congenital condition greatly increases the risks, and in some countries, is the most common cause of NNJ (Al-Sweedan et al., 2009).

Anemia in the neonates is still a major health problem in tropical Africa countries. More ever, there is currently little data on other biomarkers associated with G6PD deficiency in the absence of jaundice. Our goal was to explore potential markers of oxidative stress that are associated with G6PD deficiency at birth. Identification of such markers may help to a better understanding of the pathophysiology associated with G6PD deficiency.

\section{Material and Methods:-}

\section{Study design and research methodology:}

This study was a descriptive cross-sectional study conducted from February to June 2019. A total of 185 neonates aged $\leq 7$ days, birthed in different maternity and neonatology services in south Benin were enrolled in the study. The research work was approved by the National Research Ethics Review Boards of Benin and parents provided informed consent before been enrolled into the study.

\section{Measurement of Biochemical and Hematological Parameters:}

A venous blood sample was collected from each newborn by trained nurse. Samples were dropped from the cubital vein in ethylene diamine tetra acetic acid (EDTA) tubes for G6PD enzyme activity and in dry tubes for others biochemical and hematological parameters. The biomedical parameters were determined within 12 hours. The red cell G6PD activity was determined by an enzymatic kinetic assay for the quantitative determination of G6PD enzymatic activity using a commercial kit form Cypress Diagnostics (Cypress Diagnostics, Langdorp, Belgium). Hemoglobin $(\mathrm{Hb})$ was measured by spectrophotometry on the same sample. G6PD activity was recorded as U/g Hb. A $60 \%$ of normal activity cut-off point for the diagnosis of G6PD deficiency was established (WHO Working Group, 1989). The upper and lower limit cut-off points for moderate deficiency were respectively $60 \%$ of the normal mean and $20 \%$ of the normal mean. The upper limit for severe deficiency was $20 \%$ of the normal mean G6PD activity for neonates. Lactate dehydrogenase (LDH) and Alkalin Phosphatase ALP) activities were determined by a quantitative enzymatic method. Serum levels of Iron and Total Proteins (TP) were measured using MP Diagnostics reagents (MedicalePharmaceutique, Paris, France). The counting of the reticulocytes was done under the ordinary microscope after staining with brilliant cresyl blue.

\section{Statistical analyses:}

Data were analyzed by SigmaPlot statistical analysis software 2014 (Systat Software, Inc. San Jose, CA, USA). Means and standard errors of the mean (SEM) of blood parameters were calculated. If Normality Test (Shapiro- 
Wilk) is correct, Student's t-test was used to ascertain difference between group's characteristics, if not, MannWhitney Rank Sum Test was used. A p-value of $<0.05$ was deemed significant.

\section{Results:-}

Of the 185 newborns screened over a period of five months, more than half were boys (52.43\%) with male to female sex-ratio of 1.1:1. Their ages ranged between 1 to 7 days with an average of $3.07 \pm 0.16$ days. A total of 125 neonates (67.57\%) were 3 days old and under. The Fon (44.32\%) were the ethnic group most represented followed by the Aizo and Goun (respectively $14.05 \%$ and 12.43). Table 1 shows the demographic characteristics of the study participants.

Table 1:-Demographic characteristics of study participants, 2018

\begin{tabular}{|l|r|r|}
\hline & Number (n=185) & Percentage (\%) \\
\hline Sex & & \\
\hline Female & 88.00 & 47.57 \\
\hline Male & 97.00 & 52.43 \\
\hline Age (day) & & \\
\hline$\leq 3$ & 125.00 & 67.57 \\
\hline$>3$ & 60.00 & 32.43 \\
\hline Ethnic group & & 10.75 \\
\hline Adja & & 13.98 \\
\hline Aizo & 20.00 & 1.61 \\
\hline Bariba & 26.00 & 2.69 \\
\hline Dendi & 3.00 & 44.62 \\
\hline Fon & 5.00 & 12.37 \\
\hline Goun & 82.00 & 5.91 \\
\hline Minan & 23.00 & 8.06 \\
\hline Yoruba & 11.00 & \\
\hline
\end{tabular}

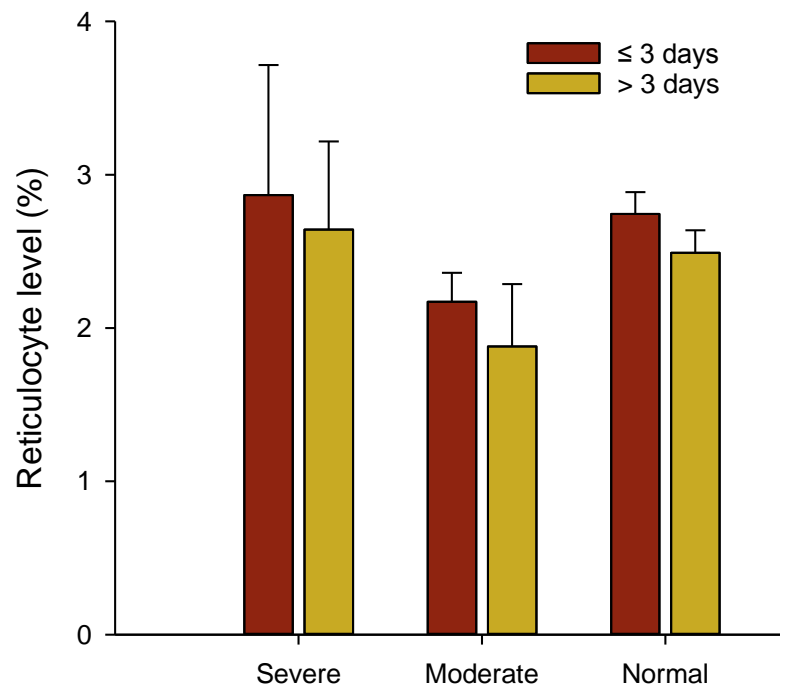

Figure 1:-Reticulocyte level in neonate

Reticulocyte level did not vary significantly in $\leq 3$ days old neonates compared to $>3$ days old in severe $(\mathrm{p}=0,530)$, moderate $(\mathrm{p}=0,836)$ and normal groups $(\mathrm{p}=0,382)($ Fig 1$)$. 
Table 2:-Glucose-6-phosphate dehydrogenase enzyme activity in neonates

\begin{tabular}{|l|c|c|c|c|}
\hline \multirow{2}{*}{ Parameter } & \multicolumn{2}{|c|}{ G6PD Enzyme Activity } & \multirow{2}{*}{ p-value } \\
\cline { 2 - 4 } & Severe & Moderate & Normal & \\
\hline Female & $2.055 \pm 0.335$ & $7.398 \pm 0.357$ & $15.886 \pm 0.471$ & $\mathrm{p}(\alpha)=0.017 ; \mathrm{p}(\beta)<0.001 ;$ \\
$\mathrm{p}(\mu)=0.025$
\end{tabular}

$\mathrm{p}(\alpha)$ : Severe vs. Normal; $\mathrm{p}(\beta)$ : Moderate vs. Normal; $\mathrm{p}(\mu)$ : Severe vs. Moderate.

The overall mean value for G6PD normal activity was $16.11 \mathrm{U} / \mathrm{g} \mathrm{Hb}$. The upper and lower limit cut-off points for moderate deficiency were $9.27 \mathrm{U} / \mathrm{g} \mathrm{Hb}(60 \%$ of the normal mean) and $3.22 \mathrm{U} / \mathrm{g} \mathrm{Hb}(20 \%$ of the normal mean), respectively. The upper limit for severe deficiency was $3.22 \mathrm{U} / \mathrm{g} \mathrm{Hb}(20 \%$ of the normal mean G6PD activity for neonates). G6PD enzyme activity level was significantly decreased in severe cases compared to normal cases (2,305 $\pm 0,142$ vs $16,249 \pm 0,320 ; \mathrm{p}(\alpha)<0.001)$, in moderate cases compared to normal cases $(7,125 \pm 0,335$ vs $16,249 \pm$ $0,320 ; \mathrm{p}(\beta)<0.001)$ and in severe cases compared to moderate cases $(2,305 \pm 0,142$ vs $7,125 \pm 0,335 ; \mathrm{p}(\mu)<0.001)$ (Table 2).

Table 3:-G6PD Statut frequency

\begin{tabular}{|c|c|c|c|c|}
\hline \multirow[t]{2}{*}{ Parameter } & \multicolumn{4}{|c|}{ G6PD Statut } \\
\hline & Normal & Moderate & Severe & Total deficit \\
\hline $\mathrm{N}(\%)$ & $141(76.22)$ & $31(16.75)$ & $13(7.03)$ & $44(23.78)$ \\
\hline \multicolumn{5}{|l|}{ Sex } \\
\hline Female & $65(73.87)$ & $21(23.86)$ & $2(2.27)$ & $23(26.13)$ \\
\hline Male & $76(78.35)$ & $10(10.31)$ & 11(11.34) & $21(21.64)$ \\
\hline \multicolumn{5}{|l|}{ Age (day) } \\
\hline$\leq 3$ & $96(76.80)$ & $23(18.40)$ & $6(4.31)$ & $29(23.20)$ \\
\hline$>3$ & $45(75.00)$ & $8(13.33)$ & $7(15.22)$ & $15(25.00)$ \\
\hline \multicolumn{5}{|l|}{ Ethnic group } \\
\hline Adja & $12(60.00)$ & $6(30.00)$ & $2(10.00)$ & $8(40.00)$ \\
\hline Aizo & $22(84.62)$ & 2(7.69) & $2(7.69)$ & $4(15.38)$ \\
\hline Bariba & $2(66.67)$ & $1(33.33)$ & $0(00)$ & $1(33.33)$ \\
\hline Dendi & $4(80.00)$ & $1(20.00)$ & $0(00)$ & $1(20.00)$ \\
\hline Fon & $63(76.83)$ & $12(14.63)$ & $7(8.54)$ & $19(23.17)$ \\
\hline Goun & $18(78.26)$ & $5(21.74)$ & $0(00)$ & $5(21.73)$ \\
\hline Minan & $6(54.55)$ & $5(45.45)$ & $0(00)$ & $5(45.45)$ \\
\hline Yoruba & $13(86.67)$ & $0(00)$ & $2(13.33)$ & $2(13.33)$ \\
\hline
\end{tabular}

A total of 44 (23.78\%) neonates were G6PD deficient, of which $13(7.03 \%)$ were severe and $31(16.75 \%)$ moderate. Among G6PD deficient neonates, $23(26.14 \%)$ were females with $2(2.27 \%)$ severe and $21(23.86 \%)$ moderate. G6PD deficient males were $21(21.65 \%)$ with $11(11.34 \%)$ severe and $10(10.31 \%)$ moderate. Frequency in $\leq 3$ days old neonates was $23.2 \%$ ( 29 neonates of 125 ) and $25.0 \%$ into $>3$ days old (15 neonates of 60). The Minan (45.45\%) were the ethnic group most affected followed by the Adja (40.00\%). Table 3shows G6PD deficiency frequencies according the demographic characteristics of the study participants.

Table 4:-Biochemical parameters in neonates

\begin{tabular}{|l|c|c|c|c|}
\hline \multirow{2}{*}{ Parameter } & \multicolumn{3}{|c|}{ G6PD Statuts } & \multirow{2}{*}{ p-Value } \\
\cline { 2 - 4 } & Normal & Moderate & Severe & \\
\hline LDH (U/L) & $291.15 \pm 19.50$ & $293.21 \pm 36.55$ & $279.57 \pm 69.32$ & $\mathrm{p}(\alpha)=0.785 ; \mathrm{p}(\beta)=0.660 ; \mathrm{p}(\mu)=0.603$ \\
\hline
\end{tabular}




\begin{tabular}{|l|c|c|c|l|}
\hline ALP (U/L) & $136.76 \pm 6.69$ & $133.56 \pm 17.23$ & $117.33 \pm 5.04$ & $\mathrm{p}(\alpha)=0.857 ; \mathrm{p}(\beta)=0.633 ; \mathrm{p}(\mu)=0.999$ \\
\hline Iron $(\mathbf{m g} / \mathbf{L})$ & $1.78 \pm 0.15$ & $1.95 \pm 0.32$ & $1.76 \pm 0.44$ & $\mathrm{p}(\alpha)=0.962 ; \mathrm{p}(\beta)=0.632 ; \mathrm{p}(\mu)=0.732$ \\
\hline TP $(\mathbf{g} / \mathbf{L})$ & $57.92 \pm 2.04$ & $57.14 \pm 5.44$ & $61.31 \pm 5.01$ & $\mathrm{p}(\alpha)=0.494 ; \mathrm{p}(\beta)=0.647 ; \mathrm{p}(\mu)=0.577$ \\
\hline
\end{tabular}

$\mathrm{p}(\alpha)$ : Severe vs. Normal; $\mathrm{p}(\beta)$ : Moderate vs. Normal; $\mathrm{p}(\mu)$ : Severe vs. Moderate.

LDH and ALP activities did not vary significantly in severe cases or moderate cases compared to normal. Iron and TP levels did not vary significantly in severe or in moderate G6PD deficient compared to normal (Table 4).

\section{Discussion:-}

G6PD deficient neonates are at risk of severe acute hemolytic anemia after exposure to oxidant stresses. We conducted this study in order to assess if biochemical markers of anemia are disrupted in G6PD deficient newborn in the absence of any oxidative attack.

The neonate enrolled ages ranged between 1 to 7 days with an average of $3.07 \pm 0.16$ days. A total of 125 neonates $(67.57 \%)$ were 3 days old and under. Of the 185 newborns screened, more than half were male $(52.43 \%)$ with a sexratio of 1.1:1. The male predominance observed in our sample reflected the distribution based on population sex reported in Benin during the 3rd General Population and Housing Census (RGPH 3) with male to female sex ratio of 1.1:1. Based on ethnicity, Fon $(44.32 \%)$ was the major ethnic group followed respectively by the Aïzo (14.05\%) and Goun (12.43\%). The overall mean value of G6PD activity in non-deficient neonate was $16.11 \mathrm{U} / \mathrm{g} \mathrm{Hb}$. This result is higher than that found by Hamid et al that was $12.8 \mathrm{U} / \mathrm{g} \mathrm{Hb}$ (Hamid et al., 2019). We used the upper (9.27 U/g Hb; $60 \%$ of the normal mean) and lower $(3.22 \mathrm{U} / \mathrm{g} \mathrm{Hb} ; 20 \%$ of the normal mean) limit cut-off points for moderate deficiency and the upper limit $(3.22 \mathrm{U} / \mathrm{g} \mathrm{Hb} ; 20 \%$ of the normal mean G6PD activity for neonates) for severe deficiency. The prevalence of G6PD deficiency in our study was $23.78 \%$ with $7.03 \%$ of severe and $16.75 \%$ of moderate deficiency. $26.14 \%$ of deficient neonates were females and $21.65 \%$ males. There was no significant difference between genders, ages and ethnics. In West Africa, G6PD deficiency ranged between $15 \%$ to $30 \%$ (Orimadegun and Sodeinde, 2011). In previous study, we reported similar level of G6PD deficiency $(24.63 \%)$ in neonate in Benin(Fiogbe et al., 2018). Such level of G6PD deficiency was reported in Northen Benin (Adedemy et al., 2015), in Nigeria (Williams et al., 2013) and in Burkina Faso (Simpore et al., 2007).

Prevalence of G6PD deficiency varies within ethnic group (Sharma et al., 2011). Our results showed that G6PD deficiency was more predominant in Mina (45.45\%) and Adja (40.00\%) ethnic groups. Marrying close family members is a tradition in many ethnic group in Benin as it is the case throughout the world (Ahmed et al., 2002; Bittles, 2001). Since Mina and Adja are among groups were first cousins marriage is predominant, the high frequency of G6PD deficiency these ethnic groups is not surprizing.

Early diagnosis for appropriate management of neonatal anemia is very important in order to prevent hyperbilirubinemia, bilirubin encephalopathy and kernicterus. Literature indicates several diagnostic tests which may be used for this purpose. LDH and ALP are predictors of hemolysis in patients with G6PD deficiency (Gaikwad and Jadhav, 2018; Nalbantoğlu et al., 2011). ALP is a ubiquitous intracellular enzyme found abundantly in red blood cells. It is secreted into plasma upon the destruction of these cells. ALP level is a significant predictor of hemolysis (Nalbantoğlu et al., 2011). Studies reported by Ylmazet al. showed high levels of ALP in patient with Rh incompatibility, in hemophagositic syndrome (Ylmaz et al., 2006) and in patients with Rh hemolytic disease (elMauhoub et al., 1989). In other hand, LDH is a true intracellular enzyme found in many body tissues particularly heart, liver, skeletal muscles, kidney and red blood cells (Wickramasinghe, 2006). Recently, Gaikwad et al. showed that serum LDH level was significantly increased in hemolytic anemia (Gaikwad and Jadhav, 2018). Similar findings were obtained in other studies (Emerson and Wilkinson, 1966; Gronvall, 1961). The possible cause for increase in serum LDH level in hemolytic anemia would be the markedly increased inflow of LDH molecules into the blood stream due to increased rate of destruction of red blood cells and slower elimination of LDH (Gronvall, 1961). Our finding that ALP and LDH activity did not vary in neonate with G6PD deficiency compared to normal suggests that hemolysis doesn't occur in G6PD deficient neonate in absence oxidative stress.

Iron is a major component of $\mathrm{Hb}$ that allows oxygen molecules fixation thereby facilitating its distribution in the body which is required for cellular respiration and other cell functions (Beard, 2001). Significantly increase in ferritin levels in G6PD deficient neonates was reported (Stadem et al., 2017). That finding supported the hypothesis of a subclinical inflammatory response in G6PD deficient neonates in the absence of jaundice or oxidative stress. I the present study, we showed that iron level did not vary in newborn with G6PD deficiency. Even if, serum ferritin 
level, not iron, reflects better iron load in individual (Siimes et al., 1974), our results does excludes iron deficiency and anemia in G6PD deficient neonate without jaundice. Significant markers of oxidative stress in African newborns with G6PD deficiency was reported. The abnormally low level of G6PD activity in newborn triggers a biologic response that includes increasing plasma levels of small molecule antioxidants such as ascorbate, uric acid and vitamin $\mathrm{E}$ in a compensatory effort (Stadem et al., 2017). This mechanism seems to be absent regarding hemolysis markers.

In the present study, we showed that anemia markers like PAL, LDH, iron, total protein and reticulocytes levels are not affected by G6PD deficiency at birth.

\section{References:-}

1. Adedemy, J.D., Gomina, M., Agossou, J., Noudamadjo, A., Mouna, E., d'Almeida, M. and AdeothyKoumakpaï, S. (2015): Prevalence of glucose 6 phosphate dehydrogenase deficiency among infants and children of Parakou, Benin. Curr. Pediatr. Res., 19(2): 58-65.

2. Ahmed, S., Saleem, M., Modell, B. and Petrou, M. (2002): Screening extended families for genetic hemoglobin disorders in Pakistan. N. Engl. J. Med., 347: 1162-1168.

3. Al-Sweedan, S.A., Jdaitawi, H., Khriesat, W.M., Khader, Y.Y. and Al-Rimawi, H.S., (2009): Predictors of severe hemolysis in patients with glucose-6-phosphate dehydrogenase deficiency following exposure to oxidant stresses. Hematol. Oncol. Stem. Cell. Ther., 2(2): 354-357.

4. Beard, J.L. (2001): Iron biology in immune function, muscle metabolism and neuronal functioning. J. Nutr., 131: $568-580$

5. Bittles, A. (2001): Consanguinity and its relevance to clinical genetics. Clin. Genet., 60: 89-98.

6. Cappellini, M.D. and Fiorelli, G. (2008): Glucose-6-phosphate dehydrogenase deficiency. Lancet, 371: 64-74.

7. Doxiadis, S.A. and Valaes, T. (1964): The Clinical Picture of Glucose-6-Phosphate Dehydrogenase Deficiency in Early Infancy. Arch. Dis. Child., 39: 545-553.

8. Drousiotou, A., Touma, E.H., Andreou, N., Loiselet, J., Angastiniotis, M., Verrelli, B.C. and Tishkoff, S.A. (2004): Molecular characterization of G6PD deficiency in Cyprus. Blood Cells. Mol. Dis., 33: 25-30.

9. El-Mauhoub, M., Parida, S.N., Kishan, J., Soni, A.L. and Nagarajan, S. (1989): Cutaneous erythropoiesis: an unusual manifestation of Rh hemolytic disease. Indian J. Pediatr., 56: 411-413.

10. Emerson, P.M. and Wilkinson, J.H. (1966): Lactate Dehydrogenase in the Diagnosis and Assessment of Response to Treatment of Megaloblastic Anaemia. Br. J. Haematol., 12(6): 678-688.

11. Fiogbe, S.E.M., Akpovi, C.D., Sègbo, J.A.G., Bognon, G., Medehouenou, M.T.C., Sagbo, G.G. and Agbangla, C. (2018): Liver function assessment in Glucose-6-Phosphate Dehydrogenase deficient neonates in Benin. Int. J. Biomed. Res., 09(06): 221-225.

12. Gaikwad, A.L. and Jadhav, D.S. (2018): Utility of serum lactate dehydrogenase in the diagnosis of megaloblastic anemia. Int. J. Res. Med. Sci., 6(9):3051-3056

13. Gronvall, C. (1961): On the serum activity of lactic acid dehydrogenase and phosphohexoseisomerase in pernicious and hemolytic anemias. Scand. J. Clin. Lab. Invest., 13: 29-36.

14. Hamid, M.M.A., Albsheer, M., Muneer, M., Altinae, L. and Lover, A.A. (2019): Prevalence and risk factors for glucose-6-phosphate dehydrogenase (g6pd) deficiency in two P. vivax malaria-endemic areas in Sudan. BMJ Glob. Health, 4: 62-72.

15. Howes, R.E., Battle, K.E., Satyagraha, A.W., Baird, J.K. and Hay, S.I. (2013): G6PD Deficiency, in Advances in Parasitology. Elsevier, pp. 133-201.

16. Mehta, A., Mason, P.J. and Vulliamy, T.J. (2000): Glucose-6-phosphate dehydrogenase deficiency. Baillieres Best Pract. Res. Clin. Haematol., 13: 21-38.

17. Nalbantoğlu, A., Ovalı, F. and Nalbantoğlu, B. (2011): Alkaline phosphatase as an early marker of hemolysis in newborns: Alkaline phosphatase in hemolysis. Pediatr. Int., 53: 936-938.

18. Noori-Daloii, M.R., Hajebrahimi, Z., Najafi, L., Mesbah-Namin, S.A., Mowjoodi, A., Mohammad Ganji, S., Yekaninejad, M.S. and Sanati, M.H. (2007): A comprehensive study on the major mutations in glucose-6phosphate dehydrogenase-deficient polymorphic variants identified in the coastal provinces of Caspian Sea in the north of Iran. Clin. Biochem., 40: 699-704.

19. Orimadegun, A.E. and Sodeinde, O. (2011): Glucose-6-phosphate dehydrogenase status and severity of malarial anaemia in Nigerian children. J. Infect. Dev. Ctries., 5(11): 792-798.

20. Ruwende, C. and Hill, A. (1998): Glucose-6-phosphate dehydrogenase deficiency and malaria. J. Mol. Med. Berl. Ger., 76: 581-588. 
21. Sharma, M., Dass, J., Dhingra, B. and Saxena, R. (2011): G6PD deficiency in females screened at tertiary care hospital. Indian J. Pathol. Microbiol., 54: 850-851.

22. Siimes, M.A., Addiego, J.E. and Dallman, P.R. (1974): Ferritin in serum: diagnosis of iron deficiency and iron overload in infants and children. Blood, 43: 581-590.

23. Simpore, J., Ilboudo, D., Damintoti, K., Sawadogo, L., Maria, E. and Binet, S. (2007): Glucose-6-Phosphate Dehydrogenase Deficiency and Sickle Cell Disease in Burkina Faso. Pakistan J. Bio. Sci., 10(3): 409-414

24. Stadem, P.S., Hilgers, M.V., Bengo, D., Cusick, S.E., Ndidde, S., Slusher, T.M. and Lund, T.C. (2017): Markers of oxidative stress in umbilical cord blood from G6PD deficient African newborns. PloS One, 12(2): e0172980

25. van den Broek, L., Heylen, E. and van den Akker, M. (2016): Glucose-6-phosphate dehydrogenase deficiency: not exclusively in males. Clin. Case Rep., 4(12): 1135-1137.

26. WHO Working Group. (1989): Glucose-6-phosphate dehydrogenase deficiency. Bull World Health Organ, 67: 601-611.

27. Wickramasinghe, S.N. (2006): Diagnosis of megaloblasticanaemias. Blood Rev., 20: 299-318.

28. Williams, O., Gbadero, D., Edowhorhu, G., Brearley, A., Slusher, T. and Lund, T.C. (2013): Glucose-6phosphate dehydrogenase deficiency in Nigerian Children. PLoS ONE, 8(7): e68800.

29. Ylmaz, S., Duman, N., Özer, Esra, Kavas, N., Ören, H., Demircioglu, F., Kumral, A., Özkan, H., Irken, G. and Özer, E. (2006): A case of rhesus hemolytic disease with hemophagocytosis and severe iron overload due to multiple transfusions: J. Pediatr. Hematol. Oncol., 28: 290-292. 